\title{
El papel de la reflexión en la hermenéutica de Hans-Georg Gadamer
}

\section{The role of reflection in Hans-Georg Gadamer's hermeneutics}

\author{
LEANDRO CATOGGIO \\ CONICET y Universidad Nacional de Mar del Plata (Argentina)
}

Recibido: 27-02-2008 Aprobado definitivamente: 10-11-2008

\section{RESUMEN}

En el presente trabajo tiene como fin exponer la función de la reflexión en la propuesta hermenéutica de Hans Georg Gadamer. Para ello se mostrará la opacidad trascendental que muestran los términos de «lenguaje» e «historia» como condiciones de posibilidad de la comprensión. Esto tiene como fin descubrir que la hermenéutica de Gadamer se estructura a partir de una semántica inefable y de una doble dimensión del lenguaje donde la reflexión crítica se sitúa como eje del diálogo hermenéutico a partir de la dialéctica de la pregunta y respuesta.

PALABRAS CLAVE

GADAMER, OPACIDAD TRASCENDENTAL, DIALÉCTICA DE LA PREGUNTA Y RESPUESTA, SEMÁNTICA INEFABLE, REFLEXIÓN HERMENÉUTICA

\section{ABSTRACT}

This paper aims to present the function of reflection in the hermeneutic proposal of Hans-Georg Gadamer showing the transcendental opacity inherent to the terms «language» and «history» as conditions of possibility for understanding. Our objective is to demonstrate that the hermeneutic of Gadamer is framed on the basis of indescribable semantics and a double dimension of language in which critical reflection constitutes the axis of the hermeneutic dialogue based on the question-answer dialectics.

\section{KEYWORDS}

GADAMER, TRASCENDENTAL OPACITY, DIALECTIC OF THE QUESTION AND ANSWER, INDESCRIBABLE SEMANTICS, HERMENEUTIC REFLECTION

\footnotetext{
(C) Contrastes. Revista Internacional de Filosofía, vol. XIV (2009), pp. 65-80. ISSN: 1136-4076 Licenciatura de Filosofía, Universidad de Málaga, Facultad de Filosofía y Letras Campus de Teatinos, E-29071 Málaga (España)
} 


\section{INTRODUCCIÓN}

El LUGAR DE LA REFLEXIÓn EN VERDAD Y MÉTODO es, en principio, crítico hacia ella misma. Gadamer desarrolla un fuerte ataque a la tradición enmarcada en la filosofía de la reflexión a partir de una enérgica defensa del pensamiento hegeliano (Gadamer, 1977, pp. 415-421). Una y otra van de la mano. A favor de la mediación histórica del conocimiento humano Gadamer argumenta que las críticas a Hegel no llegan a alcanzar el punto arquimédico de su filosofía. La filosofía hegeliana no reconoce su estructura medular en la reflexión sino el devenir histórico del contenido propio de la conciencia. Para el discípulo de Heidegger la crítica de la filosofía de la reflexión muestra en su refutación más bien «la pretensión de verdad del argumentar formal en general» (Gadamer, 1977, p. 419). Mediante sus argumentaciones dicha filosofía de la reflexión sólo refuta la formalidad de una teoría pero no el contenido verdadero de lo expuesto. Apoyándose en la carta séptima de Platón Gadamer dice que «la refutabilidad formal de una teoría no excluye necesariamente su verdad» (Gadamer, 1977, p. 419). Las críticas a Hegel en cuanto a la formalidad de sus argumentos no perjudican la verdad hermenéutica de la relación entre la historia y el evento de la verdad. De esta forma historia pasa a ser uno de los factores determinantes de la verdad hermenéutica. Podemos decir sin peligro de confundirnos que la historia (Geschichte) opera a un nivel condicionante de la comprensión (Verstehen). Ella es uno de los elementos trascendentales de la hermenéutica filosófica. Funciona a modo de principio ontológico; toda conciencia se haya determinada ontológicamente por la tradición. Ahora bien, podemos preguntarnos, entonces, ¿cuál es el papel de la reflexión en la propia hermenéutica filosófica? Para responder esta pregunta primero debemos despejar el camino y aclarar un poco más esta función de la conciencia histórica.

Que la conciencia actuante se halle determinada ontológicamente por la tradición se corresponde directamente con descripción la heideggeriana de las coordenadas interpretativas de la facticidad. El haber previo (Vorhabe) configura la praxis del sujeto en su experiencia del mundo. Este no es más que la configuración histórica de la trama de significados del Dasein en tanto ser-enel-mundo (In-der-Welt-sein). La actividad práctica se abre desde la historicidad de los conceptos constitutivos del haber previo. De esta forma, el presente se abre desde el concebir previo (Vorgriff); es decir, desde los conceptos transmitidos por la historia. En el ya famoso parágrafo treinta y dos de Sein und Zeit Heidegger explicita que la interpretación se entiende desde una conceptualidad (Begrifflichkeit) del concebir previo (Vorgriff) donde el «Sentido es el horizonte del proyecto estructurado por el haber previo (Vorhabe), la manera previa de ver (Vorsicht) y la manera de entender previa (Vorgriff), horizonte desde el cual algo se hace comprensible en cuanto algo» (Heidegger, 1998, p. 175). Esto mismo es 
lo que aparece en Gadamer como el horizonte de sentido que adquiere el nombre urbanizado de tradición. La praxis del sujeto no puede ser interpretada sino es por este horizonte configurativo de la conciencia actuante. Siempre la praxis de la vida humana debe entenderse no sólo desde el presente sino también desde este pasado determinante de la acción. El concepto operativo de la hermenéutica filosófica que describe el momento aplicativo como el espacio de intersección entre el pasado y el presente es la fusión de horizontes.

La fusión de horizontes (Horizontverschmelzung) en Verdad y Método posee la característica de ser «la forma de realización de la conversación» (Gadamer, 1977, p. 465). Esto implica que la fusión tenga la doble función de actuar tanto de forma diacrónica como de forma sincrónica. Gadamer aclara esto diciendo que sería más fecundo hablar de la función hermenéutica de la distancia que de la «distancia temporal» propiamente dicha (Gadamer, 1992, p. 16). Esta función hermenéutica de la distancia operando de forma sincrónica se realiza en el diálogo. La fusión de horizontes es la forma de desenvolvimiento de la cosa (Sache) entre los horizontes de sentido implicados en la conversación. El diálogo hermenéutico se conforma en esta operación realizando el sentido, actualizando el sentido. Esta herramienta conceptual de la hermenéutica constituye un eje primordial por el cual giran todos los objetos susceptibles de ser comprendidos. Tanto el diálogo con textos clásicos como acontecimientos históricos al igual que el proceso que guía la conversación intercultural son comprendidos bajo la fusión de horizontes. De allí que esta última se presenta como un concepto vacuo que indica la situación del evento de la comprensión. Es el término configurador que tiene la característica de mostrar el movimiento del objeto de comprensión. La fusión, de esta forma, es una noción formal (Wiehl, 2005, pp. 55-72), ${ }^{1}$ un indicador formal al modo del llamado "primer Heidegger», que describe un proceso de comprensión en que las partes implicadas se ven transformadas y se involucran en una nueva dirección significativa de la interpretación. El evento de la comprensión transforma tanto los horizontes implicados en la conversación como la interpretación heredada de lo comprendido. Como dice Jean Grondin las partes de la fusión se «metamorfosean» (métamorphosent) engendrando una nueva obra (Grondin, 2005, pp. 401-418).

El nuevo sentido acordado tiene su realización en el lenguaje debido a dos argumentos. Primero, como mencionamos, la fusión de horizontes es la forma de la conversación y; en segundo lugar, la fusión tiene su rendimiento genuino en el lenguaje. Esto mismo es lo que conlleva que no pueda darse el nuevo sentido acordado sino es por un «lenguaje común» (gemeinsame Spra-

1 Aunque no explicita el concepto de «fusión de horizontes» Wiehl subraya que todos los conceptos conductores de la argumentación gadameriana pueden comprenderse como indicadores formales de la experiencia hermenéutica. 
che) que tiene la función tanto de mostrar lo acordado como de manifestar una normatividad interpretativa de lo comprendido (Gadamer, 1977, p. 466). Ahora bien, dicha normatividad ¿se funda sobre una serie de condiciones que permiten esta construcción?; más precisamente ¿cuáles son las condiciones de posibilidad que permiten construir el nuevo objeto de comprensión basado en el acuerdo? Estas preguntas son las que nos permitirán despejar el camino y conducirnos a la pregunta fundamental sobre el lugar propio de la reflexión en la hermenéutica gadameriana.

\section{OPACIDAD TRASCENDENTAL}

Gadamer plantea al comienzo de su texto que la dirección de su investigación se puede resumir en el planteamiento sobre las condiciones de posibilidad de la comprensión (Gadamer, 1977, pp. 11-12). Karczmarczyk lo expresa del siguiente modo: «Una hermenéutica preceptiva se pregunta ¿qué debo hacer para comprender? Por el contrario para la hermenéutica filosófica la pregunta básica, análoga a las preguntas kantianas, es ¿cómo es posible la comprensión?» (Karczmarczyk, 2007, p. 45). Este cuestionamiento de remisión kantiana obedece al programa gadameriano de la búsqueda de la estructura fundamental, ontológica, del hombre en tanto ser-en-el-mundo como ente comprensor. Sin lugar a dudas esto nos lleva al programa heideggeriano de la descripción del carácter eminente de la comprensión como el elemento primordial del Dasein en su estar en el mundo en tanto es proyecto (Entwurf). Esto resulta de suma importancia no sólo por la constante referencia a la hermenéutica fenomenológica del joven Heidegger sino también por el acento «proyectivo» de la hermenéutica gadameriana.

Entonces preguntamos ¿existe en la hermenéutica gadameriana tal estructura ontológica del hombre como proyecto? No creemos, como la mayoría de los estudiosos de Gadamer, que la hermenéutica filosófica sea un constante revisionismo erudito o un simple modo deconstructivo de la precomprensión. Nadie vacila en reconocer que es este último un momento esencial de la hermenéutica; pero sólo lo es en virtud de su subordinación a la praxis actual y futura del hombre. La hermenéutica filosófica está anclada en el futuro no en el pasado. Sólo así tiene un verdadero sentido la noción y el momento de la «aplicación» en la estructura comprensiva del individuo. La aplicación es un momento constitutivo de la comprensión y como tal es la realización de la misma en la praxis humana. Que toda interpretación es aplicación se entiende según el estado proyectivo de la comprensión. Por eso entendemos que la fusión de horizontes se caracteriza no sólo por ser un concepto estructural y fenomenológico de la hermenéutica sino también por ser estructurante con respecto a la 
comprensibilidad alcanzada en el nuevo objeto conformado. Es descriptivo y configurativo de la comprensión.

Esto último se observa muy bien en la tercera parte de Verdad y Método; en el llamado carácter especulativo del lenguaje en el diálogo. Esta propiedad especulativa del lenguaje es la marca indeleble de la posibilidad de remontarnos sobre los prejuicios que determinan nuestra comprensión. Es por ello que no estamos de acuerdo con las diferencias que enumera Grondin entre Heidegger y Gadamer (Grondin, 2003, p. 137). Para Grondin el campo de aplicación de la hermenéutica heideggeriana es la existencia mientras que para Gadamer es la hermenéutica de textos. Cuestión ésta que lo lleva a pensar que la hermenéutica gadameriana es una propuesta que se circunscribe a la comprensión del sentido del texto en tanto conjunto discursivo heredado del pasado. En consonancia con esto termina por concluir que la hermenéutica gadameriana se distingue de la heideggeriana por la primacía del pasado con respecto a la primacía del futuro de la hermenéutica fenomenológica. Como se ha observado nosotros creemos que en la hermenéutica filosófica el acento está puesto en el carácter aplicativo-proyectivo de la comprensión. Si seguimos y admitimos la interpretación de Grondin entonces nos vemos obligados a desestimar el carácter aplicativo de la hermenéutica en la praxis humana. En este caso Gadamer se encontraría más cerca de Schleiermacher que de Heidegger. Pareciera que en esta visión el pensamiento gadameriano no reconozca su carácter ontológico. El vuelco al pasado no es más que el intento de la apertura del futuro en la interpretación tanto de un texto como de la vida humana misma.

De modo similar a Grondin encontramos en Escudero un planteamiento que acentúa el análisis deconstructivo del pasado sin acentuar el momento aplicativo de la comprensión. Él menciona lo siguiente: «Gadamer pone el acento con exageración en el pasado (de ahí que no sea casual que la "distancia temporal" por él auspiciada sea un criterio de índole básicamente "retrospectiva")» (Escudero, 2005, p. 149). En este caso nos parece, más bien, la exageración por parte de Escudero. Como dijimos antes es verdad que existe en la hermenéutica una clara orientación hacia el pasado pero en Gadamer la distancia temporal y su constante referencia al pasado tiene sus razones puestas en el presente y en el futuro. Esto se puede ver a partir de dos razones fundamentales de la hermenéutica ontológica. Primero: la orientación hacia el pasado tiene como fin la realización y radicalización fenomenológica de la conciencia presente a partir de la descripción de sus presupuestos. Es decir, describir ontológicamente la conciencia determinada por la historia. Segundo: dicha descripción no es más que la clarificación e iluminación de las condiciones de la comprensión para la interpretación actual de un texto o un diálogo. La dirección supuesta hacia el pasado no es más que la proyección de un sentido, un significado. El sentido siempre es sentido proyectado en la interpretación. Por eso toda comprensión 
copertenece y es consustancial con la interpretación y la aplicación. Toda comprensión es aplicatio.

En todo caso la primacía del pasado se debería entender en el sentido de aprender a escuchar los conceptos olvidados que aún nos son significativos en nuestra praxis cotidiana. La hermenéutica, si se quiere, no es más que aprender a escuchar el eco de nociones que aún nos interpelan en nuestras acciones. Las nociones de formación (Bildung) y sentido común (sensus communis) son las muestras que Gadamer ofrece en franca crítica al saber de la conciencia metodológica. La phrónesis sobre todo es el término estructural y determinante de la praxis de la vida humana. La recuperación hermenéutica de este concepto fundamental de la ética aristotélica viene a considerar el carácter proyectivo de la vida humana en una constante resignificación del pasado en cada situación concreta del presente. Tanto la Bildung como el sensus communis y la phrónesis son los conceptos conductores que describen la estructura ontológica del momento aplicativo de la comprensión. Esta tríada fenomenológica de la vida humana refleja no sólo la constitución propia de la praxis sino también la virtud hermenéutica por excelencia: la escucha de la interpelación de la tradición que nos habla como un tú lo hace a un yo.

El proyecto de la hermenéutica fenomenológica se circunscribe dentro de ciertos parámetros que pueden considerarse trascendentales a la hora de comprender la noción de «lenguaje común» que subyace a todo entendimiento acordado en la fusión de horizontes. Gadamer, a nuestro entender, sin realizar una analítica existencial mantiene la estructura de la hermenéutica como estructura ontológica de la vida humana tal como es desarrollada por Heidegger hasta Ser y Tiempo. Justamente en esta obra Heidegger define la noción de destino mediante la cual podemos observar las líneas fundamentales que va a retomar Gadamer para caracterizar la fusión de horizontes. La definición es la siguiente:

Con esta palabra designamos el acontecer originario del Dasein que tiene lugar en la resolución propia, acontecer en el que el Dasein, libre para la muerte, hace entrega de sí mismo a sí mismo en una posibilidad que ha heredado, pero que también ha elegido (Heidegger, 1998, p. 400)

Esto mismo es lo que a continuación lleva a Heidegger a decir que el Dasein es destino. El destino, entonces, es la posibilidad siempre abierta, heredada y elegida, ante la cual el Dasein toma una resolución auténtica. Elección que se restringe y se ofrece debido al carácter finito de la vida humana como intérprete de las posibilidades abiertas. La tradición enmarca el destino como la elección del intérprete ante las posibilidades heredadas. Sin duda no es otra la operación que se trasluce en la fusión de horizontes mediante su forma diacrónica. La tradición como posibilidad abierta en la cual se forja el destino es condicionante 
de la praxis humana. De allí que la historia efectual (Wirkungsgeschichte) sea no sólo el movimiento propio de la historicidad del hombre sino también la estructura ontológica que determina el momento aplicativo de la comprensión. El individuo se enfrenta mediante su elección a las posibilidades abiertas del conjunto discursivo de la tradición. Gadamer sigue manteniendo las coordenadas interpretativas del joven Heidegger. Lo que en éste último aparece como el haber previo (Vorhabe) en Gadamer se trasluce como la tradición. La estructura precomprensiva de la vida humana aparece en ambos pensadores ligada a una noción configurativa de la facticidad. En consonancia con esto los términos estructurales de la obra heideggeriana, «originario» $\mathrm{y}$ «derivado», reaparecen en Verdad y Método de un modo no explícito pero sí funcional a su desarrollo.

Esto lo encontramos sobretodo en los dos movimientos fundamentales de la hermenéutica gadameriana. Por un lado, el movimiento deconstructivo expresado en la crítica a lo que podemos llamar «conciencia metodológica»; y, por otro lado, el movimiento que desarrolla las posibilidades latentes de la historia que se reconoce en el ejercicio especulativo del lenguaje. Esto se relaciona perfectamente con las dos últimas partes de Verdad y Método. La segunda parte de la obra opera en forma sistemática contra el historicismo metodológico que tiene sus orígenes en la hermenéutica romántica desplegando un examen minucioso sobre el «cartesianismo epistemológico» de Dilthey (Cfr. Ricoeur, 1981, p. 186). ${ }^{2}$ Mientras que en la última parte nos encontramos con el desarrollo sistemático del carácter especulativo de la comprensión por medio del lenguaje. Este carácter especulativo del lenguaje es el medio que tiene la comprensión de ir más allá o en contra de la determinación de la tradición en nuestras acciones. Es la forma que adquiere el entendimiento de ir contra todo dogmatismo. Más adelante nos detendremos en ello y veremos que lo especulativo es el momento reflexivo crítico de la comprensión.

Estos son los ejercicios hermenéuticos que nos acercan al evento de la comprensión de la vida humana. La finitud como el elemento primordial y definitorio del individuo se corresponde con un conocimiento de sí mismo sustentado sobre dos configuradores que funcionan al modo de a priori del conocimiento humano: la historia y el lenguaje. Para la hermenéutica las condiciones de todo conocimiento elaborado por ella son estos a priori que operan de forma estructural en la comprensión. Ellos determinan la praxis del ser humano tanto como su condición finita. Pero la operacionalidad de estos a priori no se define como la hace la tradición trascendental de la filosofía. Estos a priori están sujetos a impredecibles variaciones según sus diferentes contenidos (Cfr.

2 Ricoeur resume claramente el planteo gadameriano de esta segunda parte en «tres puntos anti-metodológicos»: la rehabilitación de los prejuicios, la rehabilitación de la tradición y la rehabilitación de la autoridad. 
Wachterhauser, 2002, p. 57). Es decir, su funcionalidad se encuentra restringida a los contenidos contingentes de la praxis. Es, justamente, debido a esto que no podemos tener un conocimiento de estos a priori. En la hermenéutica no hay una accesibilidad cognitiva a sus condicionantes. En otras palabras, no hay una transparencia total del funcionamiento de los mismos. Tanto la historia como el lenguaje que constituyen y determinan la estructura de la vida humana son inaccesibles a la finitud cognitiva del sujeto. Por más que se intente rodear los posibles caminos que tomen estos condicionantes nunca se alcanzan a encerrar en una certeza sapiente.

En resumidas cuentas, esto nos lleva, por un lado, a la determinación finita del conocimiento humano; y, por otro lado, a comprender que es imposible aprehender con certeza la estructura a priori del sujeto. En la hermenéutica gadameriana no se pueden transparentar las condiciones trascendentales de la praxis humana (Cfr. Wachterhauser, 2002, p. 58). Existe en la hermenéutica filosófica una opacidad natural en el conocimiento debido al carácter finito del ser humano. No sólo la historia no es traslúcida sino también el lenguaje a pesar de ser el medio de comprensión por el cual actuamos y nos entendemos con otros en el mundo. Tanto el trato con los entes intramundanos como el trato con los demás individuos que completan mi entorno se encuentran opacados por una limitación inherente a mi propia condición comprensiva. La pre-comprensión no es enteramente transparente a la reflexión subjetiva. La trilogía terminológica de prejuicios-tradición-autoridad es proyectiva sobre el desarrollo de la vida humana. Ellos son los elementos articuladores que se manifiestan en la expresión lingüística. Es el lenguaje como el lugar de sedimentación de la tradición donde la historia se manifiesta con su fuerza comprensiva del mundo. Es allí donde se delimita el horizonte de comprensión que nos remite a nuestro carácter finito y es, a su vez, donde la elección establece el destino humano. La lingüisticidad es el nombre gadameriano para el a priori que configura nuestra comprensión de una forma inaccesible.

\section{ESPECULACIÓN Y REFLEXIÓN}

Anteriormente habíamos mencionado que el carácter especulativo del lenguaje viene a considerar el elemento hermenéutico crítico que logra elevarse sobre el conjunto discursivo heredado del pasado. Gadamer explica la noción de la siguiente manera:

Especulativo es lo contrario del dogmatismo de la experiencia cotidiana. Es especulativo el que no se entrega directa o indirectamente a la solidez de los fenómenos o a la determinación fija de lo que se opina en cada caso, sino que sabe reflexionar; 
hegelianamente hablando, que reconoce el «en sí» como un «para mí». Y una idea es especulativa cuando la relación que se enuncia en ella no puede pensarse como atribución inequívoca de una determinación a un sujeto, de una propiedad a una cosa dada, sino que hay que pensarla como una relación refleja en la que lo uno es lo uno de lo otro y lo otro es lo otro de lo uno. (Gadamer, 1977, p. 558).

Aquí Gadamer retoma de Hegel la relación interna entre la reflexión y lo especulativo. El movimiento propio de la hermenéutica es pensar estos términos desde el centro del lenguaje. A partir de esto la hermenéutica gadameriana retoma el vínculo etimológico entre «especulativo» y speculum (espejo) que encuentra desarrollado en el pensamiento de Tomás de Aquino. Esto le permite considerar el carácter propio del enunciado como un reflejo, una imagen del original que es duplicación (representación) de lo reflejado. Es, justamente, la reflexión la que indica que el «en sí» de la cosa presente es una duplicación, un speculum, de la presencia del ente en el intérprete. El enunciado espeja y, por tanto, duplica en su imagen la unidad conceptual del horizonte del intérprete. El enunciado es un momento del horizonte de significación que constituye el hablante. Lo dicho no es más que una presentación, un hacerse presente, del conjunto discursivo que precede y posibilita todo decir. La potencialidad propia del horizonte de significación implica la realización en el presente como la actualización temporal del sentido. La realización es actualización del significado. Este viene a ser el momento de la aplicatio de la comprensión. El momento aplicativo de la interpretación alcanzada reside en el espejarse el conjunto discursivo heredado del pasado en el enunciado. El habla es la aplicación realizativa del significado que se configura en el presente.

El juego que ofrece lo especulativo reside, justamente, en esta actualización continua del significado en el presente. Esto implica que la hermenéutica sólo acepte parcialmente el pensamiento hegeliano en torno a lo especulativo. Al reconsiderar esta concepción hegeliana desde el centro del lenguaje la diferencia que Gadamer va a remarcar con Hegel se basa en el papel de la reflexión en este movimiento especulativo del lenguaje. El autor de Verdad y Método explica que Hegel «sólo pretende extraer del lenguaje el juego reflexivo de sus determinaciones del pensamiento, y elevarlo por el camino de la mediación dialéctica, dentro de la totalidad del saber sabido, hasta la autoconciencia del concepto» (Gadamer, 1977, p. 561). Así como anteriormente observamos que Gadamer tiene una postura defensiva con Hegel respecto de las críticas esgrimidas por la filosofía de la reflexión aquí vemos que se distancia de él, justamente, en lo que concierne al movimiento reflexivo del concepto en el enunciado. Esto no implica necesariamente una contradicción ni una ambigüedad en la postura gadameriana. Los enfoques críticos con respecto a la filosofía de la reflexión y el la filosofía hegeliana son distintos. Con respecto al primero la crítica se enfoca 
desde una dirección histórica y sobre la diferencia entre lo formal y el contenido. Para Gadamer toda refutación formal sólo demuestra el modo argumentativo formal y no un ataque propio a la verdad expresada. En su crítica al papel de la reflexión en lo especulativo de la dialéctica hegeliana el enfoque, en cambio, se aborda desde el centro hermenéutico del lenguaje. La hermenéutica no va a aceptar que la dialéctica del concepto quede sumergida en una reflexión interna del enunciado. Para Gadamer la dialéctica hegeliana «reposa objetivamente en la sumisión del lenguaje a su "enunciación"» (Gadamer, 1977, p. 560).

La reflexión, de esta forma, queda presa de las determinaciones especulativas del concepto manifestadas en la predicación según la filosofía hegeliana. Ya en un trabajo anterior a Verdad y Método se indica que «el límite puesto a la lógica del enunciado desde ella misma no se puede definir realmente en Hegel, y es preciso recurrir a las ciencias de la experiencia histórica, que se imponen contra Hegel» (Gadamer, 1992, p. 58). Gadamer, que toma distancia de esta forma con el pensamiento hegeliano, no es muy claro en lo que respecta a su noción de «reflexión» en esta parte de su texto. En su intento de no caer ni en un pensamiento reflexivo formal ni en una reflexión interna al enunciado crítica ambas posturas pero sin explicar qué entiende él por dicho concepto. Lo que sí podemos encontrar es un camino prelimar que nos conduce hacia el encuentro con la operatividad de la reflexión en la hermenéutica. Este trayecto ya lo hemos comenzado a transitar en su versión «negativa». Sabemos que la postura gadameriana no acepta ni el papel externo de la reflexión sugerido por la tradición reflexiva de la filosofía ni una reflexión interna que se quede únicamente en la dimensión enunciativa del lenguaje. Justamente una distinción entre dimensiones del lenguaje será el punto crucial que lleva a la hermenéutica a desplazar la reflexión del fuero interno del enunciado y ubicarla en un contexto más amplio.

Gadamer va a distinguir dos dimensiones del lenguaje. Una dimensión es la del enunciado. Dimensión en la cual se ubica, para este filósofo, la filosofía moderna en general y, como hemos visto, Hegel. Otra dimensión, la propiamente hermenéutica, es la dimensión expresiva del lenguaje. Gadamer distancia someramente dichas dimensiones. El enunciado para la hermenéutica comporta dos características básicas. Por un lado, manifiesta una reducción de sentido del horizonte de significación del intérprete. Por otro lado, representa una acepción desenfocada del habla cotidiana. La distinción de fondo de ambas dimensiones se encuentra entre «lo dicho» y «el querer decir». El enunciado corresponde a los simplemente dicho. Que el horizonte de significación quede meramente en lo dicho implica que las posibilidades de actualización del significado se vean reducidas a lo puesto en el enunciado y no a otras viables interpretaciones. Gadamer utiliza para esto el ejemplo del interrogatorio judicial. En el interrogatorio es notorio que surja una discrepancia entre lo dicho y lo que se quería decir. El hablante enuncia algo que queda sellado en el escrito del protocolo 
judicial. Lo puesto escrito limita y clausura toda posible significación de lo que el interrogado quería verdaderamente decir. Surge una distancia entre lo que queda dicho y lo que realmente se quería decir. Allí se observa la restricción significativa del enunciado y al mismo tiempo el desenfoque que se produce entre lo dicho y el querer decir.

Para Gadamer el lenguaje no se consume en enunciados que hacen una abstracción de lo que no se dice expresamente (Cfr. Gutiérrez, 2002, p. 228). El lenguaje, como mencionamos antes, es la realización del sentido; más exactamente, es la realización del horizonte de significación del intérprete. El horizonte se actualiza en el momento interpretativo de la comprensión mediante la fusión del presente y el pasado. El significado no sólo se ve determinado por el presente sino que se encuentra íntimamente ligado al conjunto discursivo que lo precede y conforma la posibilidad de realización de la expresión. En todo acto interpretativo la estructura precomprensiva opera configurando el significado en el presente. La dimensión expresiva del lenguaje remite al conjunto de la relación lenguaje-mundo-intérprete como un evento donde se manifiesta el sentido. Es una actualización interna al horizonte de significación que tiene una doble remisión. Por un lado, remite a la referencia presente que el intérprete intenta comprender; $y$, por otro lado, remite a la infinitud de sentido de lo no abarcado en el enunciado. La expresividad propia de la lengua converge en ambas direcciones remitidas. El enunciado no agota el sentido. De allí que para Gadamer «el que habla se comporta especulativamente en cuanto sus palabras no copian lo que es, sino que expresan y dan la palabra a una relación con el conjunto del ser (Gadamer, 1977, p. 561).

La hermenéutica, de esta forma, se distancia de la concepción del lenguaje a partir de la lógica. Para la primera la lógica sólo se queda en el nivel del enunciado del habla. Esto no sólo significa un recorte de la productividad propia del lenguaje sino también el desconocimiento de la realización fáctica de la expresión. La hermenéutica excede el sentido semántico del enunciado. La actualidad realizativa del significado implica la productividad del lenguaje. Este en su nivel expresivo manifiesta el evento de la comprensión del ser humano como el momento aplicativo-realizativo del significado. Lo especulativo se ofrece, según esto, como la indicación lingüística de la relación finito-infinito de la palabra. Cada expresión como evento del sentido remite a la finitud de la referencia presente (lo dicho) y a la infinitud de lo no dicho en el enunciado (el querer decir). Es esto mismo lo que entiende Gadamer por la «dialéctica de la palabra». La palabra no es más que una dimensión interna de multiplicación; se ofrece como un centro que vincula lo finito con el todo:

Cada palabra hace resonar el conjunto de la lengua a la que pertenece, y deja aparecer el conjunto de la acepción del mundo que le subyace. Por eso cada palabra, 
como acontecer de un momento, hace que esté ahí también lo no dicho, a lo cual se refiere como respuesta y alusión (Gadamer, 1977, p. 549)

Esto no debe entenderse como la relación entre lo particular y lo universal. Aquí no nos encontramos con una transparencia total del significado. En esta relación opera la opacidad natural que conlleva el lenguaje como condición de acepción del mundo. El «todo» es un todo que engloba el evento del sentido pero al cual no se puede acceder mediante una reflexión interna del enunciado. La hermenéutica excede el nivel semántico del enunciado pero eso no implica que dicho nivel semántico de la hermenéutica se haga transparente por medio de la reflexión subjetiva. La semántica hermenéutica es una semántica inefable (Cfr. Kusch, 1989, p. 256). Que la semántica resulte inefable no implica que no exista sino que, para la hermenéutica, con la noción de de expresividad abre un campo de mayor trascendencia de la noción de significatividad. La funcionalidad especulativa del lenguaje permite abrir el horizonte de la palabra en su dialéctica interna de constante multiplicación significativa.

Esto debe entenderse a partir de lo que Gadamer llama «la regla hermenéutica». La misma, de origen retórico, considera la realización del sentido como un espiral en que el todo determina a la parte; y, a su vez, la parte determina al todo (Cfr. Gadamer, 1977, p. 360). Es una vieja regla de la hermenéutica que bien podemos observar en la metodología interpretativa de textos de Schleiermacher. Para esta hermenéutica metodológica cada fragmento de un texto sólo es comprensible y susceptible de interpretación si el mismo es articulado en función a la totalidad del texto; y éste último sólo es comprensible desde la interpretación de sus fragmentos. La dialéctica de la palabra es la versión de esta regla hermenéutica que toma como centro especulativo el lenguaje. El evento de la comprensión en la dimensión expresiva del lenguaje se expresa en una unidad de sentido que abarca tanto la referencia inmediata del significado como una multiplicidad no dicha. La unidad de sentido implica la solidaridad de los términos finitud e infinitud. Son instancias de la unidad de sentido que no se traslucen en dicotomías como la de universal-particular o sensible-inteligible. Si hay que adecuarlos a una dicotomía propia de la tradición filosófica podríamos nombrar la distinción aristotélica de dynamis y enérgeia. Posibilidad y actualización son las correspondientes características de la expresión. La unidad de sentido manifiesta las diversas posibilidades realizativas del significado mientras que el momento aplicativo de la hermenéutica es la realización de una de esas posibilidades. Como bien señala Günter Figal la actualidad del significado muestra la presentación de una posibilidad de significación limitada sólo por la perspectiva del intérprete. ${ }^{3}$

3 El texto es el siguiente: «The actuality of meaning should rather be considered as a presentation of a possibility, which is never fully realized. It possesses determinateness only 
La comprensión humana se da a través de las posibilidades abiertas de la significatividad. La productividad del lenguaje es lo dicho en el enunciado y lo no dicho por él. Por eso se entiende que «la inteligencia del lenguaje hermenéutico nos prohíbe tomar los enunciados al pie de la letra. Señala la infinitud de lo que se quiere decir. Hay que recurrir a otras palabras, tonos, formas de silencio, para comprender lo que el lenguaje está queriendo decir» (Grondin, 2003, p. 224). La semántica es inefable porque es inacabable, siempre la finitud y la infinitud se encuentra en constante relación. Pero esta inacababilidad no debe entenderse a partir de una noción de progreso sino desde la diferencia. Siempre se comprende de modo distinto, no mejor. Comprender lo que el lenguaje está queriendo decir es el punto hermenéutico por excelencia. Es allí donde entramos en la dimensión hermenéutica del lenguaje: en la posibilidad de comprender de manera diferente. La esencia de la experiencia hermenéutica se constata en su movimiento negativo. Comprender a partir de otra posibilidad de la significatividad, del querer decir del lenguaje, es comprender de manera distinta. La dynamis interna de la palabra es la que permite la posibilidad de comprender siempre de un modo distinto. El lenguaje debido a esta capacidad de actualizarse cada vez de un modo diferente cobra una inagotabilidad de sentido que nosotros lo remarcamos como una semántica inefable.

Ahora bien, se puede preguntar cómo se da el paso de una dimensión enunciativa del lenguaje a una dimensión expresiva del lenguaje. Pues bien, es aquí donde nos encontramos con el elemento metodológico gadameriano: la dialéctica de la pregunta y la respuesta; más precisamente, el carácter eminente de la pregunta. Ésta tiene la función de abrir la estrechez del significado en «lo dicho» y remitirnos a la dimensión del «querer decir». Por eso Gadamer se encarga de mostrar que la dimensión del enunciado se encuentra supeditada a la motivación. Cada enunciado dicho está motivado (ist motiviert) por una pregunta (Cfr. Gadamer, 1992, p. 58). No es el enunciado en sí mismo el que tiene la prioridad lógica sino la motivación de la pregunta que lo precede y direcciona. La pregunta es el eje por el cual nos movemos especulativamente desde lo dicho a lo no dicho, desde la actualización del significado hasta su potencialidad. Esto es lo que lleva a Gadamer a decir que «no hay ningún enunciado que no sea fundamentalmente una especie de respuesta. Por eso la comprensión de un enunciado tiene como única norma suprema la comprensión de la pregunta la que responde» (Gadamer, 1992, p.58).

De hecho el enunciado tiene sentido sólo en virtud de su pertenencia al horizonte de significación en la situación interrogativa. El enunciado se estructura, entonces, a partir de tres funciones hermenéuticas. Desde el horizonte de 
significación como actualización; presentación de una posibilidad de la potencia expresiva del lenguaje. En segundo lugar, como signo de lo no dicho en el mismo enunciado. El enunciado señala no sólo una actualización de las posibilidades de sentido del mismo sino también un conjunto discursivo presupuesto en la comprensión. Y, en tercer lugar, se configura desde una situación; es decir, desde un contexto determinado y desde el otro interlocutor al que va dirigido el enunciado, sea este una persona o un texto. La interpelación discursiva, de esta manera, se coloca como el modo de acceso que capaz de pasar desde esta dimensión del enunciado a la dimensión expresiva del lenguaje. Con ello ganamos una mayor amplitud semántica de la palabra y reconocemos el espacio pragmático en el que se desarrolla. La reflexión hermenéutica recibe su tematización en esta operación que realiza la pregunta como movimiento especulativo del lenguaje. El carácter eminente de la pregunta como reflexión hermenéutica hace que «lo dicho nunca posee su verdad en sí mismo, sino que remite, hacia atrás y hacia adelante, a lo no dicho» (Gadamer, 1992, p. 151).

La reflexión hermenéutica es el desplazamiento continuo que realiza la pregunta desde la dimensión del enunciado a la dimensión expresiva del lenguaje. Pero, a diferencia del movimiento especulativo hegeliano, aquí no nos encontramos con una reflexión puramente interna del enunciado. Haciéndose eco de la interpretación de Bubner la hermenéutica filosófica plantea una inversión del planteamiento hegeliano (Cfr. Gadamer, 1992, p. 261). De hecho, Rüdiger Bubner interpreta que «estar inmerso en la tradición no significa únicamente estar atado a la particular influencia marcada por una situación sino que significa también verse confrontado a una variedad inagotable de posibilidades» (Bubner, 1992, p. 14). Para Gadamer la aparición de las distintas figuras del espíritu deben comprenderse de una manera retrospectiva; es decir, desde adelante hacia atrás: desde el sujeto a la sustancia. O sea, desde la actualización del significado hacia el horizonte de significación o desde el enunciado hasta la dimensión expresiva. De allí que la reflexión hermenéutica sea un momento pleno de la comprensión humana y la situación interrogativa el medio por el cual nos ubicamos en la función hermenéutica de la lingüisticidad (Sprachlichkeit).

\section{CONCLUSIÓN}

Por lo que hemos podido observar el papel de la reflexión en la hermenéutica se sitúa en el movimiento que realiza la pregunta al abrir el espacio significativo del enunciado al desplazarlo hacia la dimensión expresiva del lenguaje. De esta manera, en el diálogo que mantenemos con otro intérprete o un con un texto la situación interrogativa que surge del contexto dialogal permite que la reflexión crítica desoculte la opacidad del conjunto histórico-discursivo de la comprensión. 
Una desocultación que tiene la característica de ser interminable. El lenguaje nunca se agota en lo dicho. Esta funcionalidad de la reflexión le permite a Gadamer responder a la crítica habermasiana de «conservador» mediante distintas operaciones de la reflexión hermenéutica. Para el caso, a partir la situación interrogativa la reflexión crítica de la hermenéutica es capaz de descubrir las falsas objetivaciones de los conceptos. Otro ejemplo de su operación es la de confrontar el análisis lógico de los enunciados que aplica determinados criterios de cálculo enunciativo a textos filosóficos (Cfr. Gadamer, 1992, p. 246). En suma, el valor propio de la reflexión hermenéutica descansa en el hecho de rehusarse a toda pretensión dogmática de la interpretación. Con ello toda situación dialógica es una fusión de horizontes donde la dialéctica de la pregunta y respuesta quiebra todo sentido restringido al enunciado e involucra reflexivamente una desocultación tanto de los prejuicios determinantes de la interpretación como de las posibilidades infinitas de significación. Es, entonces, en este punto donde el «lenguaje común» se manifiesta como principio y fin de la comprensión hermenéutica. Hay un acuerdo prescrito de escucharse mutuamente y dar lugar a la situación interrogativa como dar lugar a la posibilidad de comprenderse mutuamente en el acuerdo sobre la interpretación. Es decir, el lenguaje común refiere tanto a una situación interrogativa como a una reflexión crítica ligada sustancialmente a ella. Sólo es posible lograr un acuerdo interpretativo mediante una reflexión crítica integrada a la comunidad de diálogo.

\section{REFERENCIAS BIBLIOGRÁFICAS}

BUBNER, R. 1992: «Acerca del fundamento del comprender» en Isegoría, 5, 1992, pp. 5-16

ESCUDERO, A. 2005: «Hermenéutica de la verdad: el problema de los criterios» en Oñate, T-García Santos, C.-Quintana Paz, M (ed.). Hans Georg Gadamer: Ontología estética y hermenéutica. Madrid: Dykinson.

FIGAL, G. 2002: «The doing of the thing itself» en Dostal, R. (ed.) The Cambridge Companion to Gadamer, Cambridge: Cambridge University Press.

GADAMER, H-G. 1977: Verdad y Método. Salamanca: Sígueme.

GADAMER, H-G. 1992: Verdad y Método II. Salamanca: Sígueme.

GRONDIN, J. 2003: Introducción a Gadamer. Barcelona: Herder.

GRONDIN, J. 2005: «La fusion des horizons. La version gadamérienne de l'adaequatio rei et intellectus?» en Archives de philosophie, 68.

GUTIERREZ, C. 2002: Temas de filosofía hermenéutica: conferencias y ensayos. Bogotá: Universidad Nacional de Colombia.

HEIDEGGER, M. 1998: Ser y Tiempo. Santiago de Chile: Editorial Universitaria, 1998.

KARCZMARCZYK, P. 2007: Gadamer: aplicación y comprensión. La Plata: Edulp. 
KUSCH, M. 1989: Language as calculus vs. language as universal medium. A study in Husserl, Heidegger and Gadamer. Dordrecht: Kluwer Academic Publishers.

RICOEUR, P 1981: «Logique hermeneutique?» en Guttorm, F. (ed.) Contemporary philosophy. Boston-London: Martines Nijhoff Publishers.

WACHTERHAUSER, B. 2002: «Getting in Right: Relativism, Realism and Truth» en Dostal, R. (ed.) The Cambridge Companion to Gadamer, Cambridge: Cambridge University Press.

WIEHL, R. 2005: «Arte del concepto e historia del concepto en la hermenéutica filosófica de Hans-Georg Gadamer» en Oñate, T-García Santos, C.-Quintana Paz, M (ed.). Hans Georg Gadamer: Ontología estética y hermenéutica. Madrid: Dykinson.

Leandro Catoggio es Profesor en Filosofía por la Universidad Nacional de Mar del Palta y actual doctorando en Filosofía por la Universidad Nacional de Lanús

\section{Publicaciones recientes:}

Catoggio, Leandro y Crelier, Andrés. «Hegel después de la hermenéutica de la facticidad: apuntes sobre la interpretación apeliana y gadameriana de la dialéctica». Artículo completo en Cechetto, Sergio y Catoggio, Leandro (comp.) Esplendor y miseria de la filosofía hegeliana, Mar del Plata, Suárez, 2007, ISBN: 987-1314-29-4.

Catoggio, Leandro Martin. «La "comunidad de conversación”: la relación entre discurso y comunidad en la organización social desde la hermenéutica de Gadamer». Artículo completo en: Primeras Jornadas de Jóvenes Investigadores en Ciencias Sociales, $1^{\text {a }}$ edición -Mar del Plata: ISBN 978-98723504-2-0. Agremiación Docente Universitaria Marplatense, 2007. 1. Investigación en Ciencias Sociales CDD300.7

\section{Línea de investigación:}

Hermenéutica. Hans-Georg Gadamer y la relación entre hermenéutica y retórica en función de la racionalidad práctica.

\section{Dirección postal:}

España 3261, Mar del Plata, CP: 7600; provincia de Buenos Aires, Argentina

Dirección electrónica: leamarcat@yahoo.com.ar 